\title{
Acta Cardiologica
}

\section{Paradoxical nonreentrant Tachycardia induced by iatrogenic atrioventricular Block --Manuscript Draft--}

\begin{tabular}{|c|c|}
\hline Manuscript Number: & AC-2018-00335R1 \\
\hline Article Type: & IMAGE FOCUS \\
\hline Keywords: & $\begin{array}{l}\text { Arrhythmia; nonreentrant atrioventricular nodal tachycardia; dual pathway; } \\
\text { mechanical block; Congenital heart disease }\end{array}$ \\
\hline & BELGIUM \\
\hline \multicolumn{2}{|c|}{$\begin{array}{l}\text { Corresponding Author Secondary } \\
\text { Information: }\end{array}$} \\
\hline \multicolumn{2}{|c|}{ Corresponding Author's Institution: } \\
\hline \multicolumn{2}{|c|}{$\begin{array}{l}\text { Corresponding Author's Secondary } \\
\text { Institution: }\end{array}$} \\
\hline \multicolumn{2}{|c|}{ First Author Secondary Information: } \\
\hline \multirow[t]{5}{*}{ Order of Authors: } & Mieke / Roggen, M.D. \\
\hline & Christophe Garweg, M.D. \\
\hline & Rik Willems, M.D., PhD \\
\hline & Marc Gewillig, M.D., PhD \\
\hline & Joris Ector, M.D., PhD \\
\hline \multicolumn{2}{|c|}{ Order of Authors Secondary Information: } \\
\hline \multirow{3}{*}{ Response to Reviewers: } & $\begin{array}{l}\text { Reviewer \#2: No specific comment } \\
\text { No references in the Image Focus format. We leave the decision to in- or exclude the } \\
\text { references to the editor. } \\
\text { We greatly appreciate the opportunity to publish this article. }\end{array}$ \\
\hline & Sincerely yours, \\
\hline & On behalf of all authors: \\
\hline
\end{tabular}


Mieke Roggen,

Christophe Garweg,

Rik Willems,

Marc Gewillig,

Joris Ector.

Additional Information:

Question

Response

Grants:

No

Did you receive any grants to run your study?

Manuscript:

No

Did you structure your text in sections i.e. introduction, methods, results, discussion and conclusion?

\section{Acknowledgements:}

Yes

Did you submit written permission from publishers or patients?

\section{Publication Agreement:}

Yes

Did you upload your declaration "Conflict of Interests" signed by all Co-Authors if any?

\section{Reprinting:}

You have the option of reprints i.e. 50 reprints at minimum. Please let us know if you want reprints! 


\section{Paradoxical nonreentrant Tachycardia induced by iatrogenic atrioventricular Block}

Mieke Roggen, M.D., Christophe Garweg, M.D., Rik Willems, M.D., PhD., Marc Gewillig, M.D., PhD., Joris Ector, M.D., PhD.

Department of Cardiology and Pediatric Cardiology, University Hospital Leuven, Belgium.

$\underline{\text { Address for correspondence: }}$

Joris Ector, M.D., PhD

Cardiology

University Hospital Gasthuisberg

Herestraat 49

B-3000 Leuven

Belgium, Europe

Phone: +32-16-34 4248 Fax: +32-16-34 4240

E-mail: Joris.Ector@uzleuven.be

Keywords: Arrhythmia; nonreentrant atrioventricular nodal tachycardia; dual pathway;

mechanical block; congenital heart disease;

Total word count: 496

\section{$\underline{\text { Acknowledgments }}$}

Joris Ector is supported by a research grant from the Fund for Scientific Research-Flanders.

Mieke Roggen is supported by the Eddy Merckx Pediatric Cardiac Research Fund. 


\section{Image Focus}

2 A 5 week old male infant with complex congenital heart disease underwent cardiac

3 catheterization and balloon dilatation of a banded pulmonic artery. He was born with a

4 univentricular heart: double inlet left ventricle with L-loop. He had undergone a surgical

5 correction for aortic coarctation and pulmonic artery banding in the first week of life.

6 The electrocardiogram before the catheterization procedure showed a normal PR interval.

7 During the procedure, transient mechanical total atrioventriculair (AV) block occurred due to

8 contact between the intracardiac balloon and the AV conduction system. At the end of the

9 procedure, AV conduction improved to a pronounced atrioventricular delay with a PR interval

10 of $390 \mathrm{~ms}$, and the patient was admitted to the intensive care unit to monitor AV conduction.

11 In the subsequent hours, he developed paroxysms of narrow-QRS tachycardia at a rate of 230

12 bpm showing 'one to two' conduction over the AV node, with each $\mathrm{P}$ wave followed by two

13 QRS complexes with alternating R-R interval (figure). He was treated with a low dose of 14 intravenous metoprolol without clear effect on the tachycardia episodes; intravenously 15 administered amiodarone with cooling resulted in acceptable rate control. After one day, the 16 PR interval decreased again to $140 \mathrm{~ms}$ and the episodes of tachycardia disappeared, without 17 recurrence during follow-up.

18 'One to two' tachycardias over the AV-node are well known and caused by dual fast and slow

19 AV nodal pathway conduction. ${ }^{1}$ Our case however is the first report describing a 'one to two' 20 tachycardia caused by iatrogenic slowing of the AV nodal conduction due to mechanical 21 block. The most probable explanation for our findings is transient block of the fast antegrade 22 AV-nodal pathway, and concurrent slowing of the antegrade slow pathway resulting in 23 pronounced first-degree atrioventriculair block. When antegrade fast pathway conduction 24 recovers, 'one to two' conduction over the fast and slow pathway results in tachycardia. When 25 also slow pathway conduction improves later on, 'one to two' conduction is no longer 
26 possible because of the refractoriness of the His-Purkinje system after the previous impulse

27 over the fast AV nodal pathway, resulting in disappearance of the tachycardia episodes.

28

29

30 Disclosure of interest

31 The authors report no conflicts of interest.

32

33

\section{References}

1. Peiker C, Pott C, Eckardt L, Kelm M, Shin DI, Willems S, Meyer C. Dual atrioventricular nodal non-re-entrant tachycardia. Europace 2016; 18(3):322-9. 


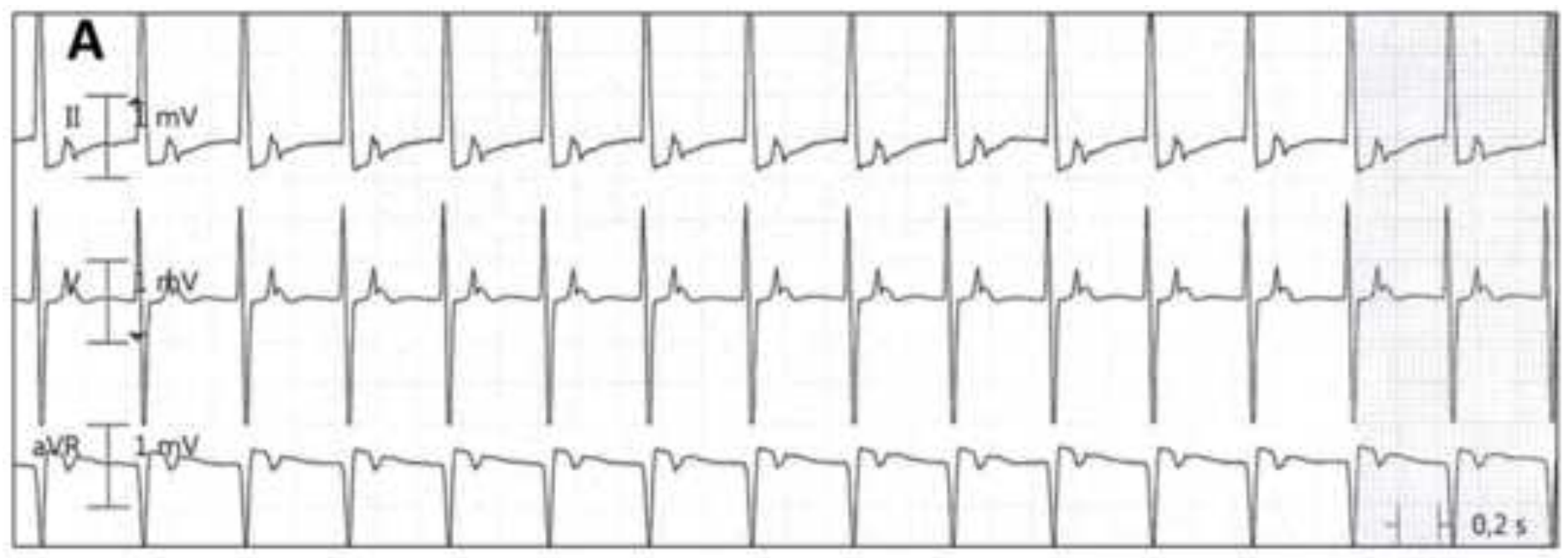

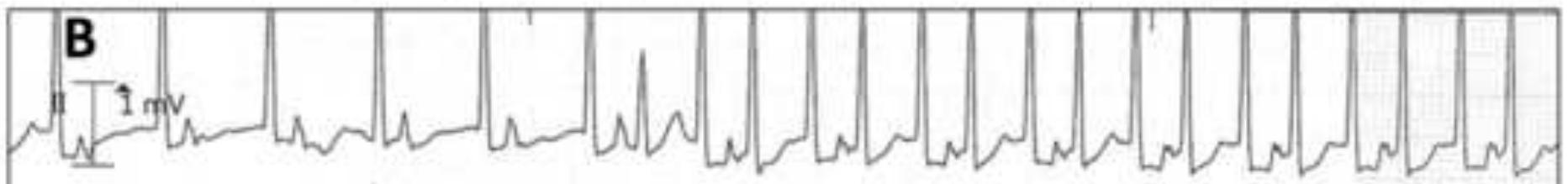

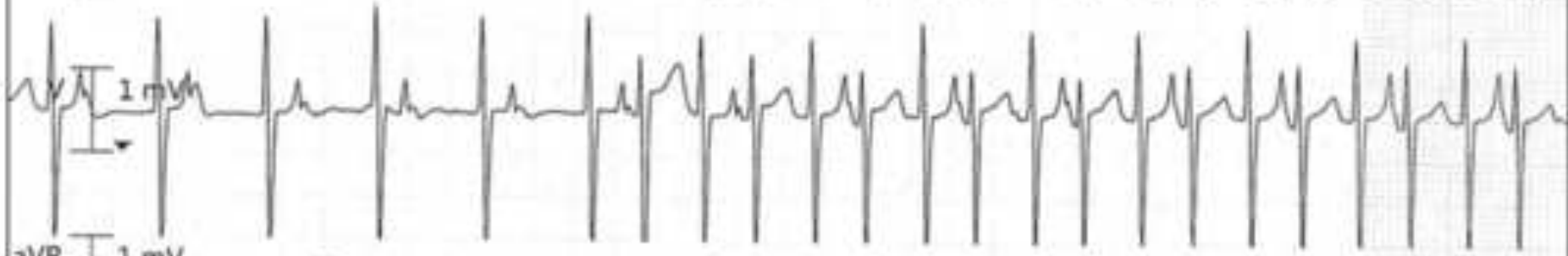

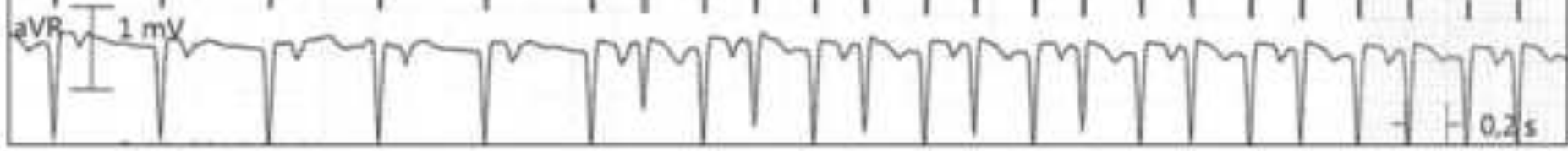

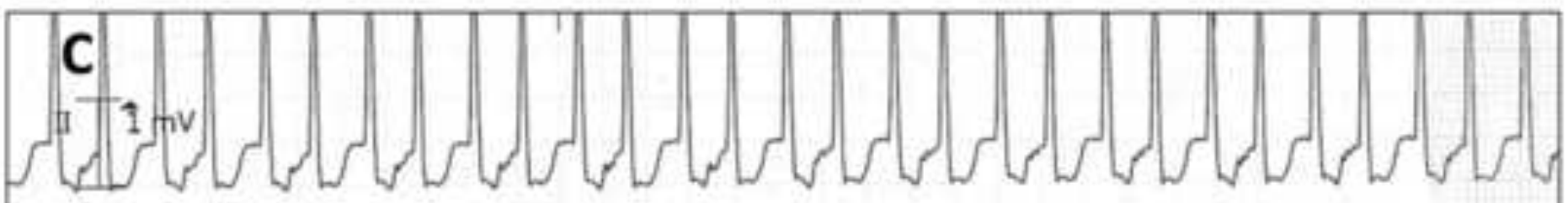

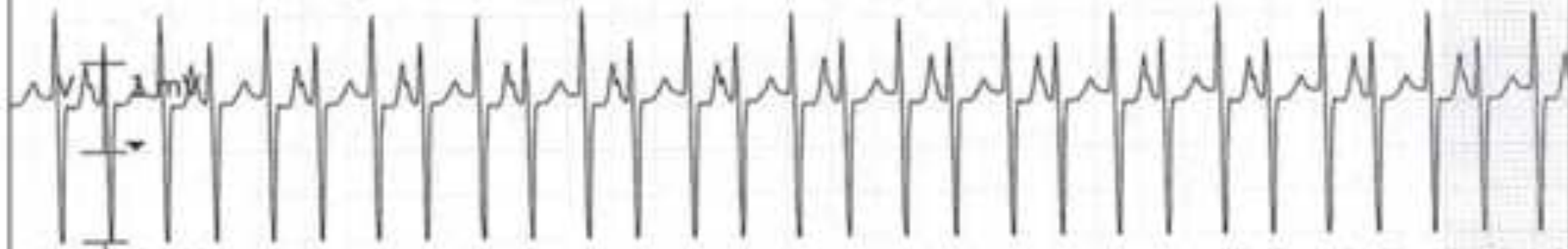
- 


\section{$1 \quad$ Figure Legend}

2

3 Electrocardiographic monitoring of leads II, V1 and aVR .

4 A: Pronounced PR prolongation after the balloon dilatation procedure. There is a one to one P/R relationship $5 \quad$ with a PR interval of $390 \mathrm{~ms}$

6 B: Initiation of a one to two tachycardia over the AV-node, showing a one to two P/R relationship with marked $7 \quad$ QRS-alternans and alternating R-R interval.

8 C: Continuation of the one to two tachycardia in subsequent hours, until improvement in AV nodal conduction 9 makes one to two conduction impossible and normal one to one AV-conduction is restored. 
Click here to access/download;Conflict of Interests;Conflicts of $\underline{\underline{\Perp}}$ Interest.docx

\section{$\underline{\text { Conflicts of Interests }}$}

The author report no conflicts of interest 


\section{$\underline{\text { Acknowledgments }}$}

Joris Ector is supported by a research grant from the Fund for Scientific Research-Flanders.

Mieke Roggen is supported by the Eddy Merckx Pediatric Cardiac Research Fund. 